\title{
СРАВНИТЕЛЬНЫЙ АНАЛИЗ СУБЬЕКТОВ ДАЛЬНЕГО ВОСТОКА МЕЖДУ СОБОЙ ПО СОЦИАЛЬНО-ЭКОНОМИЧЕСКИМ ПОКАЗАТЕЛЯМ ЗА ПЕРИОД 2005-2017 ГОДОВ
}

\author{
Уиаков Е. $A$. \\ Тихоокеанский институт географии ДВО РАН, Владивосток \\ ushakov.tig.dvo@gmail.com
}

\begin{abstract}
Аннотация. В статье рассматривается вопрос различия социально-экономического развития субъектов между собой по различным статистическим показателям. Для этого был рассчитан специальный коэффициент, с помощью которого проанализировано развитие субъектов по отношению друг к другу и динамика этого коэффициента. Для его полнейшего анализа был взят период с 2005 по 2017 г. с рассмотрением трехлетних периодов и каждого года в отдельности. Были посчитаны значения коэффициента по всем регионам с выделением регионов с наибольшими и наименьшими значениями. Показаны субъекты с наиболее положительной или отрицательной динамикой данного коэффициента. В ходе анализа коэффициента были выявлены взаимосвязи развития регионов между собой в период социально-экономических кризисов и восстановительного периода после них. Было определено, что развитие регионов зависело от их специализации, экономико-географического и транспортно-географического положения, агломерационного эффекта, а также качества управления. На примере субъектов Дальневосточного региона был произведен региональный анализ данного коэффициента. Особенным отличием Дальнего Востока от других регионов являлось то, что это территория нового освоения с активным развитием добывающих производств. Были даны объяснения динамики коэффициента на примере субъектов этого региона с их определенной особенностью. Была выделена взаимосвязь между коэффициентом сравнения социально-экономических показателей с размером ВРП на душу населения и их сходная динамика. Также было установлено, что высокие показатели коэффициента прежде всего зависят от наличия добывающей промышленности в субъектах и от ее высокой доли в структуре ВРП. Другие факторы для этого коэффициента оказались менее значимы. К ним можно отнести обрабатывающие производства, транспорт, наличие больших и крупных городов для субъектов Дальнего Востока. Также была выявлена взаимосвязь динамики коэффициента по годам среди субъектов и вызвавшие их социально-экономические явления. Как было установлено, динамика коэффициента сравнения социально-экономических показателей имело общую характеристику для большинства субъектов Дальневосточного региона.
\end{abstract}

Ключевые слова: социально-экономическое развитие, коэффициент сравнения социально-экономических показателей, региональный уровень, кризисные явления, субъекты, Дальний Восток. 


\title{
COMPARATIVE ANALYSIS OF FAR EAST SUBJECTS BETWEEN YOURSELF BY SOCIO-ECONOMIC INDICATORS FOR THE PERIOD OF 2005-2017
}

\author{
Ushakov E. A. \\ Pacific Geographical Institute FEB RAS, Vladivostok
}

Annotation. The article considers the issue of differences in the socio-economic development of the subjects among themselves according to various statistical indicators. For this, a special coefficient was calculated, with the help of which the development of regions in relation to each other and the dynamics of this coefficient are analyzed. For its fullest analysis, took the period from 2005 to 2017 with a consideration of three-year periods and each year separately. The coefficient values were calculated for all regions with the allotment of regions with the largest and smallest values. The subjects with the most positive or negative dynamics of this coefficient are shown. During the analysis of the coefficient, the interconnections of the development of regions among themselves during the period of socio-economic crises and the recovery period after them were revealed. It was determined that the development of regions depended on their specialization, economic-geographical and transport-geographical position, agglomeration effect, as well as the quality of management. On the example of the subjects of the Far Eastern region, a regional analysis of this coefficient was carried out. A special difference between the Far East and other regions was that this territory of new mastering with the active development of extractive industries. Explanations of the dynamics of the coefficient were given by the example of the subjects of this region with their specific feature. The relationship between the coefficient of comparison of socio-economic indicators with the size of GRP per capita and their similar dynamics was highlighted. It was also found that high coefficient ratios primarily depend on the availability of extractive industries in the subjects and, first of all, on its high share in the structure of GRP. Other factors for this coefficient were less significant. These include manufacturing industry, transport, the presence of large and large cities for the subjects of the Far East. The relationship between the dynamics of the coefficient over the years among the regions and the socio-economic phenomena that caused them was also revealed. As it was established, the dynamics of the coefficient of comparison of socio-economic indicators bore a common characteristic for most subjects of the Far Eastern region.

Key words: socio-economic development, coefficient of comparison of socio-economic indicators, regional level, crisis phenomena, subjects, the Far East.

Субъекты Российской Федерации имеют большие различия в социально-экономическом развитии. Этому может служить ряд факторов - используемый природно-ресурсный потенциал, экономико-географическое и транспортно-географическое положение, историческое развитие, агломерационный эффект, специализация, а также ряд других географических факторов. Важно понимать, что изменение в социально-экономическом положении и развитии региона также зави- 
сят от качества управления ими со стороны федеральных и местных властей.

Одним из показателей социально-экономических различия субъектов может служить их сравнение между собой по социально-экономическим показателям с помощью подсчета определенного коэффициента. Для расчета этого коэффициента было взято 17 социально-экономических показателей на душу населения, из которых 5 количественных и 12 стоимостных (которые учитывались с учетом стоимости жизни в регионах). Это были как демографические показатели (динамика численности населения), социальные показатели (безработица, среднемесячная заработная плата и др.), так и экономические (объем отгруженных товаров, инвестиции и др.).

При расчёте использовался система подсчета для субъектов, в которых получившиеся максимальный социально-экономический показатель был равен 1, а минимальный $-0:\left(\mathrm{X}=\left(\mathrm{P}_{\mathrm{reg}}-\mathrm{P}_{\min }\right) /\left(\mathrm{P}_{\max }-\mathrm{P}_{\min }\right)\right)$. Все получившиеся расчетные данные в дальнейшем суммировались и делились на количество социально-экономических показателей $\left(\mathrm{K}=\left(\mathrm{X}_{1}+\mathrm{X}_{2}+\ldots+\mathrm{X}_{17}\right) / \mathrm{N}\right.$, где $\mathrm{N}-$ количество социально-экономических показателей). Если получившиеся коэффициент был ближе к 1, то субъект выглядит более благополучным по отношению к другим. Если коэффициент близок к 0, то и субъект смотрится на фоне других менее развитым. Также по полученным данным можно рассматривать динамику субъектов по отношению друг к другу (по годам или за определенный период).

При подсчете коэффициента и его анализе было взято 83 субъекта Российской Федерации (на 2005 г.), в т. ч. с учетом того, что ряд бывших автономных округов вошли в состав «материнских» территорий, которые учитывались уже вместе с ними. Стоит учитывать, что данное количество показателей за этот период было взято с учетом всех возможных статистических данных, поскольку ряд показателей не был найден из-за проблем со статистическими данными на территории Чеченской республики в середине 2000-х гг.

Во время исследования брался период за 2005-2017 гг. с ежегодным анализом. По результатам подсчета большинство субъектов имели показатели в пределах 0,200-0,300. Например, 2005 г. показатель выше 0,300 имели 20 субъектов, ниже 0,200 - 7 субъектов. Приблизительно такие же данные сохранились и в 2017 г. (выше 0,300 - 19 субъектов, ниже 0,200 - 7 субъектов). Лидерами по этому 
Лидеры и аутсайдеры среди субъектов при их сравнении по социально-экономическим показателям

\begin{tabular}{|c|c|c|}
\hline 2005 & 2011 & 2017 \\
\hline \multicolumn{3}{|c|}{ Регионы-лидеры } \\
\hline Ненецкий $\mathrm{AO}-0,572$ & Ненецкий $\mathrm{AO}-0,653$ & Ненецкий АО - 0,664 \\
\hline $\begin{array}{c}\text { Тюменская область - } \\
0,558\end{array}$ & Тюменская область - 0,532 & $\begin{array}{c}\text { Сахалинская область - } \\
0,491\end{array}$ \\
\hline $\begin{array}{c}\text { Хантыл-Мансийский } A O \\
-0,552\end{array}$ & $\begin{array}{c}\text { Ханть-Мансийский } A O- \\
0,480\end{array}$ & Тюменская область - 0,478 \\
\hline $\begin{array}{c}\text { Ямало-Ненеикий } A O- \\
0,616\end{array}$ & $\begin{array}{c}\text { Ямало-Ненеикий } A O- \\
0,640\end{array}$ & $\begin{array}{c}\text { Xанть-Мансийский } A O- \\
0,431\end{array}$ \\
\hline Москва- 0,468 & Москва $-0,448$ & $\begin{array}{c}\text { Ямало-Ненеикий } A O- \\
0,665\end{array}$ \\
\hline Чукотский $\mathrm{AO}-0,426$ & Санкт-Петербург - 0,430 & Санкт-Петербург - 0,429 \\
\hline Санкт-Петербург - 0,386 & $\begin{array}{c}\text { Сахалинская область - } \\
0,407 \\
\end{array}$ & Москва $-0,415$ \\
\hline Татарстан - 0,379 & Татарстан - 0,396 & Татарстан - 0,387 \\
\hline Липецкая область - 0,372 & Чукотский $\mathrm{AO}-0,388$ & $\begin{array}{c}\text { Московская область - } \\
0,383\end{array}$ \\
\hline Омская область - 0,360 & $\begin{array}{c}\text { Белгородская область - } \\
0,384 \\
\end{array}$ & $\begin{array}{c}\text { Белгородская область - } \\
0,381 \\
\end{array}$ \\
\hline \multicolumn{3}{|c|}{ Регионы-аутсайдеры } \\
\hline $\begin{array}{c}\text { Курганская область - } \\
0,212\end{array}$ & Адыгея - 0,216 & $\begin{array}{c}\text { Северная Осетия-Алания } \\
-0,195\end{array}$ \\
\hline Бурятия - 0,209 & $\begin{array}{c}\text { Северная Осетия-Алания } \\
-0,208 \\
\end{array}$ & Еврейская АО - 0,194 \\
\hline Дагестан - 0,204 & Курганская область - 0,203 & $\begin{array}{c}\text { Кабардино-Балкария - } \\
0,190\end{array}$ \\
\hline Приморский край - 0,195 & Ивановская область - 0,198 & Алтай - 0,186 \\
\hline $\begin{array}{c}\text { Кабардино-Балкария - } \\
0,194 \\
\end{array}$ & $\begin{array}{c}\text { Кабардино-Балкария - } \\
0,194 \\
\end{array}$ & $\begin{array}{c}\text { Курганская область - } \\
0,182 \\
\end{array}$ \\
\hline $\begin{array}{c}\text { Ивановская область - } \\
0,187\end{array}$ & Тыва $-0,174$ & Чечня $-0,174$ \\
\hline Адыгея - 0,181 & $\begin{array}{c}\text { Карачаево-Черкессия - } \\
0,165\end{array}$ & Тыва $-0,173$ \\
\hline Тыва - 0, 178 & Калмыкия - 0,164 & Калмыкия - 0,150 \\
\hline Чечня - 0,097 & Чечня $-0,134$ & $\begin{array}{c}\text { Карачаево-Черкессия - } \\
0,148\end{array}$ \\
\hline Ингушетия $-0,050$ & Ингушетия - 0,107 & Ингушетия - 0,111 \\
\hline
\end{tabular}

Рассчитано по данным Росстата [5-10]. 
показателю являются Ненецкий АО, Тюменская область и ее автономные круга, Москва, Санкт-Петербург, Татарстан, а главными аутсайдерами Чечня, Ингушетия, Тыва, а также в последние годы Карачаево-Черкессия и Калмыкия (табл. 1).

Важно выделить ряд периодов для динамики этого коэффициента. В нашем случае были взяты периоды: 2005-2008 гг., 2008-2011 гг., 2011-2014 гг., 2014-2017 гг. Первый период значился как годы, при которых шел активный социально-экономический рост. Следующий период - как кризисный, при котором шло сочетание кризиса 20082009 гг. с резким снижением социально-экономических показателей, а в 2010-2011 гг. происходило их активное восстановление. Период 2011-2014 гг. характеризовался незначительным ростом в социально-экономической сфере страны. А 2014-2017 гг. характеризовались как период с новым витком социально-экономического кризиса.

Первый период характеризовался более активным ростом регионов Урала и Поволжья (Челябинская область, Пермский край, Курганская область, Свердловская область, Татарстан, Ульяновская и Пензенская области). Среди лидеров оказались регионы с ростом нефтедобычи - Сахалинская область и Ненецкий автономный округ. Также за счет местных факторов и качества управления развитие получили Калужская область и Белгородская область. За счет бюджетных вливаний Чечня. Среди главных аутсайдеров оказались регионы Северо-Востока - Якутия и Чукотка, а также Тюменская и Омская области, и приграничные Псковская и Смоленская области, а также депрессивные регионы Калмыкия и Карачаево-Черкессия. Данное падение было вызвано перерегистрацией ряда крупных местных компаний в Москву или падением качества управления этими регионами. Все годы этого периода по динамике среди регионов схожи между собой. Большие отличия по годам заключаются лишь в том, что 2006 г. имел наименьшее количество регионов с ростом коэффициента, а 2008 г. наибольшее их количество с ростом связи с моментом наступления социально-экономического кризиса.

Кризисный период 2008-2011 гг. показал, что наиболее активно падение происходило в нефтедобывающих регионах (Ханты-Мансийский $\mathrm{AO}$ ), промышленных регионах Урала или других сталелитейных субъектах - прежде всего Вологодская область и отчасти Липецкая область. Также снижение коэффициента продолжили депрессивные субъекты - Калмыкия и Карачаево-Черкессия. Наиболее позитивная 
ситуация была в субъектах Дальнего Востока, а также в Северном (Мурманская область, Коми, Ямало-Ненецкий АО) и Северо-Западном (Санкт-Петербург, Ленинградская и Новгородская области) регионах. Также за счет местных факторов продолжила получать развитие Калужская область. 2009 г. характеризовался наибольшим ростом коэффициента в подавляющем большинстве регионов. Исключением стал Урал, где большинство субъектов, прежде всего промышленных, показали снижение этого показателя. А 2010 и 2011 гг. стали восстановительным периодом после кризиса - для большинства субъектов был характерен отрицательный рост на фоне восстановления промышленных регионов и ресурсодобывающих регионов (из-за большого роста и восстановления цен ни их продукцию на мировых рынках). Рост показателя в 2011 г. был характерен прежде всего для центральной части России и большинства субъектов Дальнего Востока.

Период 2011-2014 гг. в коэффициенте имел негативную динамику для большинства субъектов. Рост в основном происходил в северной части Европейской России и полосой на юг до регионов центрального Черноземья, которые стали лидерами по динамике данного коэффициента - Курская, Воронежская, Липецкая, Тамбовская области. Также лидерами были регионы нефтедобывающего роста (Сахалинская область и Ненецкий АО), Калининградская область и Чеченская республика. Главными аутсайдерами стали Кемеровская область, Алтай, Еврейская АО и Чукотский АО. Стоит отметить, что для промышленных регионов динамика коэффициента была более отрицательна, чем для других. В целом 2012 г. характеризовался практически повсеместным ростом коэффициента практически по всем регионам, а 2013 и 2014 г. наоборот - подавляющее большинство имели снижение.

Новый кризисный период 2014-2017 гг. характеризуется снижением коэффициента у промышленных районов с выделением географической зоны на Урале и Сибири. Наибольший рост показателя наблюдается прежде всего на Дальнем Востоке и значительной части европейских регионов страны. Связи с наступлением кризиса 2015 и 2016 гг. имели вновь по большинству субъектов рост за счет более отрицательных показателей в промышленных регионах. 2017 г. характеризовался отрицательным ростом показателя практически по всем субъектам, что свидетельствует о стабилизации социально-экономической сферы после кризиса (его прохождение), несмотря на отрицательные и слабоположительные динамики показателей по итогам года (рис. 1). 


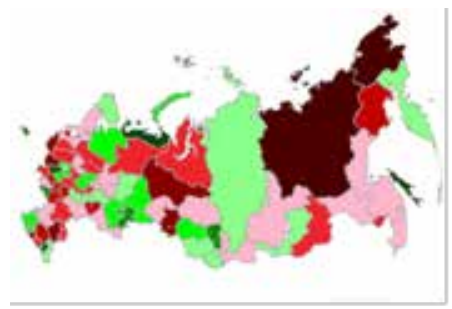

2005-2008

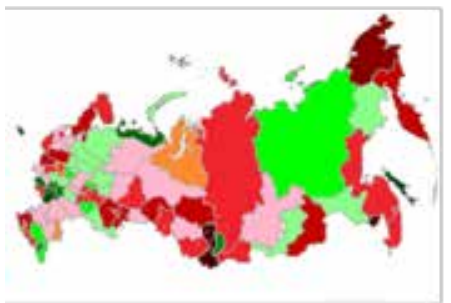

2011-2014

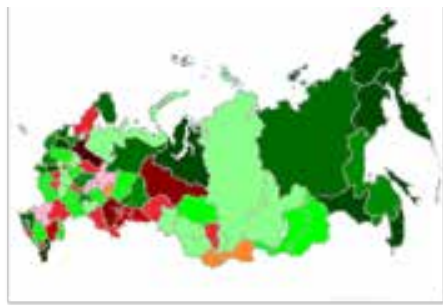

2008-2011

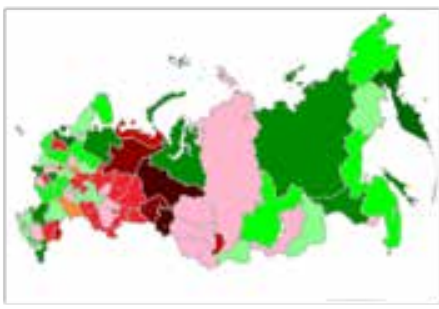

2014-2017

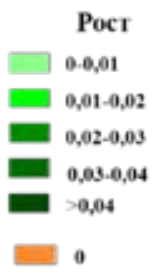

Снижение

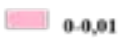

$0.01-0,02$

$0,02-0,03$

$0,03-0,04$

$>0,04$

Рис. 1. Динамика коэффициента соотношения социально-экономических показателей

Одним из ярких примеров показательности коэффициента сравнения социально-экономических показателей является Дальневосточный регион России. Этот регион в целом выделяется особо хорошей динамикой коэффициента в рассматриваемый период. Необходимо указать, что регион является территорией недавнего освоения. Обширная его часть до сих пор не освоена или историческое развитие территории и производства на ней идет недавно [1-2, 12-13]. В связи с этим доля обрабатывающей промышленности региона не столь значительна и колеблется на уровне менее $10 \%$ в структуре ВРП в большинстве субъектов (около 10 \% на юге региона Амурская область, Приморский и Хабаровский край). В целом же главным видом деятельности является добывающая промышленность, которая возросла в последние годы в структуре ВРП. Так ряд регионов входят в число лидеров по России по доле добычи полезных ископаемых в структуре ВРП - Сахалинская и Магаданская области, Якутия и Чукотский АО. Также особую роль играет транспорт. Но его роль не столь значительна, как добывающие производства (табл. 2).

Рост показателя в этих регионах шел прежде всего за счет добывающей промышленности. Притом взаимосвязь между этими показателями высокая. В целом для регионов имелась общая тенден- 
Таблица 2

Ряд показателей по субъектам Дальневосточного региона

\begin{tabular}{|c|c|c|c|c|c|c|c|c|}
\hline & \multicolumn{4}{|c|}{2005} & \multicolumn{4}{|c|}{2017} \\
\hline & 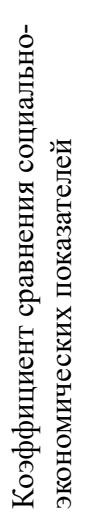 & 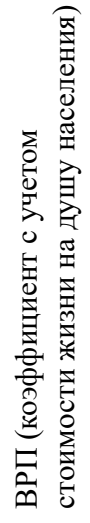 & 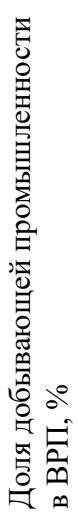 & 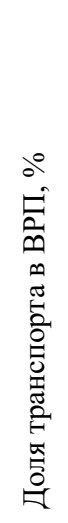 & 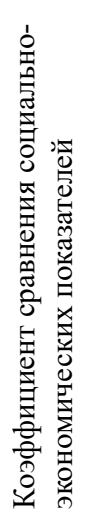 & 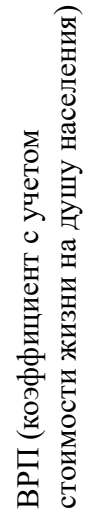 & 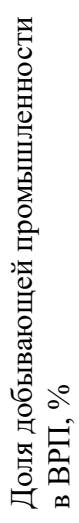 & 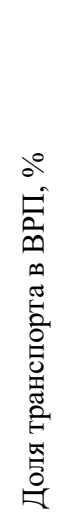 \\
\hline $\begin{array}{l}\text { Республика Саха } \\
\text { (Якутия) }\end{array}$ & 0,327 & 28,67 & 39,5 & 7,2 & 0,364 & 50,89 & 48,2 & 7,6 \\
\hline Камчатский край & 0,222 & 15,80 & 3,9 & 6,4 & 0,295 & 26,17 & 6,2 & 5,2 \\
\hline Приморский край & 0,195 & 15,28 & 1,6 & 22,0 & 0,247 & 23,69 & 0,9 & 21,1 \\
\hline Хабаровский край & 0,233 & 18,46 & 4,7 & 19,1 & 0,259 & 28,04 & 6,0 & 20,2 \\
\hline Амурская область & 0,221 & 16,07 & 5,3 & 27,2 & 0,287 & 21,93 & 12,1 & 16,8 \\
\hline Магаданская область & 0,282 & 24,43 & 27,1 & 7,7 & 0,317 & 50,90 & 38,4 & 5,9 \\
\hline Сахалинская область & 0,298 & 30,97 & 22,1 & 8,8 & 0,491 & 87,73 & 60,0 & 4,2 \\
\hline Еврейская АО & 0,226 & 14,30 & 0,5 & 25,3 & 0,194 & 19,10 & 8,9 & 15,3 \\
\hline Чукотский АО & 0,426 & 23,40 & 7,5 & 8,3 & 0,372 & 59,81 & 43,5 & 5,3 \\
\hline
\end{tabular}

ция динамики. Так в 2006 году подавляющее большинство регионов имело снижение коэффициента, а в 2009 году на фоне социально-экономического кризиса рост показателя был повсеместным, который в 2010 г. заменился снижением, а на следующий год очередным ростом, который опять заменился снижением и стабилизацией показателя в большинстве регионов (рис. 2). В целом стоит отметить, что Дальневосточный регион выглядел негативно по отношению к другим регионам России в период 2005-2008 гг. и отчасти в период 2011-2014 гг. А наиболее положительная динамика была в периоды 2008-2011 гг., и 2014-2017 гг. - период кризисов, что говорит о наибольшей устойчивости Дальневосточного региона в кризисы при сравнении с другими регионами страны. 


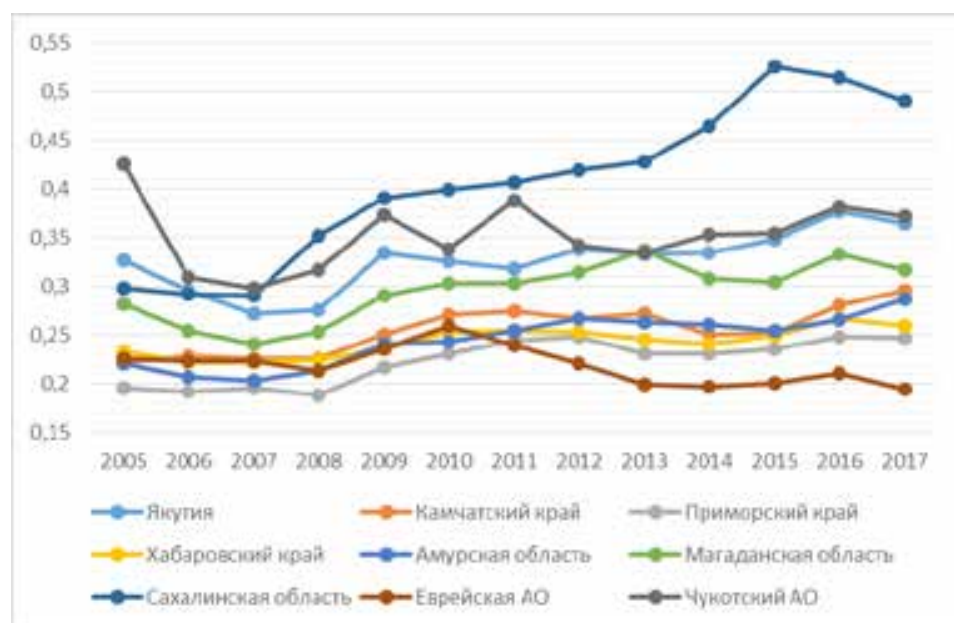

Рис. 2. Динамика коэффициента сравнения социально-экономических показателей по регионам Дальневосточного региона

В целом главными факторами при изменении коэффициента служат следующие.

Специализация регионов - промышленные регионы в рассматриваемом периоде испытывают снижение показателя. Особо важным является добывающая промышленность.

Экономико-географическое положение - ярким примером служит Дальний Восток, который имеет рост коэффициента за счет экономических связей и активного товарооборота со странами Азиатско-Тихоокеанского региона, прежде всего Китая.

Транспортно-географическое положение - это полностью характерно для приграничных и прибрежных субъектов Дальнего Востока [15].

Качество управления - оно зависит как от качества управления со стороны местных (региональных) властей, так и стороны федерального центра по отношению к региону, проводимой к нему социально-экономической политики. Это могут быть, например, инвестиции со стороны федерального бюджета для проведения каких-либо мероприятий и связанные с этим осуществления инвестиционных проектов, введение льготных режимов или отдельных постановлений, связанных со стимулированием социально-экономических процессов в регионе. 
Историческое развитие - это главным образом связано со становлением специализации региона, которое служит как фактор развития региона в прошлом, который может служить и в настоящем и будущем. Данный фактор характерен для староосвоенных регионов западной части страны. Дальний Восток является регионом нового освоения, поэтому здесь низка доля обрабатывающей промышленности, которая в большинстве регионов компенсируется добывающей промышленностью за счет природных ресурсов [11].

При сравнении с ВРП необходимо указать, что существует четкая взаимосвязь между коэффициентом и величиной ВРП региона на человека. В целом регионы-лидеры по ВРП сходны с лидерами по рассматриваемому коэффициенту. Аналогичная ситуация касается и аутсайдеров по данному коэффициенту. Яркими примерами являются Сахалинская область (как лидер по ВРП и коэффициенту) и Еврейская автономная область (как аутсайдер по ВРП и коэффициенту). Аналогичной ситуацией можно назвать и сходство динамики ВРП и коэффициента. Регионы с большей динамикой ВРП имеют более положительный рост коэффициента, а регионы с наименьшей динамикой ВРП испытывают более отрицательный рост коэффициента.

Такая же тенденция прослеживается и у регионов с довольно развитой промышленностью в структуре ВРП. Особенно это касается добычи полезных ископаемых в отличие от обрабатывающих производств. Главная зависимость идет прежде всего от вида добываемых ресурсов - это прежде всего нефть и газ. На развитие региона они сказывают сильное влияние, если добываются в значительном количестве $[3-4,14]$. Обрабатывающая промышленность имеет не столь большое влияние на сам коэффициент, но динамика его производства может подтолкнуть к росту рассматриваемого коэффициента.

Агломерационный эффект оказывает положительную роль на значение коэффициента в регионах с наличием больших городов. Здесь высока зависимость от развитости большого города, доли городского населения, а также наличия других больших городов в субъекте. Регионы с сельской местностью имеют более низкие показатели коэффициента.

Благодарность: Исследование выполнено при финансовой поддержке РФФИ в рамках научного проекта № 17-05-41044 


\section{Литература}

1. Бакланов П. Я. Территориальные структуры хозяйства в региональном управлении. Москва: Наука, 2007. 237 с.

2. Геосистемы Дальнего Востока России на рубеже XX и XXI веков: в 3 т. T. 3. Территориальные социально-экономические системы. Владивосток: Дальнаука, 2012. $364 \mathrm{c}$.

3. Мошков А. В. Структурные изменения в региональных территориально-отраслевых системах промышленности Российского Дальнего Востока. Владивосток: Дальнаука, 2008. 266 с.

4. Мошков А. В. Структурные сдвиги в промышленном производстве Тихоокеанских регионов России // Ученые записки Государственного Забайкальского университета. 2015. № 1. С. 98-106.

5. Регионы России: Социально-экономические показатели 2007. Статистический сборник. М.: Росстат, 2007. 991 с.

6. Регионы России: Социально-экономические показатели 2010. Статистический сборник. М.: Росстат, 2010. 996 с.

7. Регионы России: Социально-экономические показатели 2012. Статистический сборник. М.: Росстат, 2012. 990 с.

8. Регионы России: Социально-экономические показатели 2013. Статистический сборник. М.: Росстат, 2013. 990 с.

9. Регионы России: Социально-экономические показатели 2016. Статистический сборник. М.: Росстат, 2016. 1326 с.

10. Регионы России: Социально-экономические показатели 2018. Статистический сборник. М.: Росстат, 2018. 1162 с.

11. Романов М. Т. Территориальная организация хозяйства слабоосвоенных регионов России. Владивосток: Дальнаука, 2009. 317 с.

12. Стратегия территориальной организации хозяйства Приморского края. Владивосток: Дальнаука, 1991. 260 с.

13. Тихоокеанская Россия: страницы, прошлого, настоящего, будущего. Владивосток: Дальнаука. 406 с.

14. Baklanov P. Ya., Moshkov A. V. Structural transformation of the economy in the Pacific region of Russia and efficiently trends // R-ECONOMY. 2016. № 1. P. 51-66.

15. Baklanov P. Ya., Romanov M. T., Karakin V. P., Lankin A. S. Projects of Development of Transcontinental Transport-Economic Belts in Northern Russia // Journal of Resources and Ecology. 2015. № 6. P. 110-113.

\section{References}

1. Baklanov P. Ya. Territorial'nyye struktuty khozyaystva $v$ regional'nom upravlenii [Territorial structures of economy in the regional management]. Moscow, Nauka Publ., 2007. 239 p.

2. Geosistemy Dal'nego Vostoka Rossii na rubezhe XX i XXI vekov: v 3 t. T. 3. Territorial'nye social'no-ekonomicheskie sistemy [Geosystems of the Far East of Russia on a boundary of the 20th-2 $1^{\text {st }}$ centuries: in three volumes. Volume 3 . Territorial socialeconomic structures]. Vladivostok, Dalnauka Publ., 2012. 364 p. 
3. Moshkov A.V. Strukturnye izmeneniya v regional'nyh territorial'no-otraslevyh sistemah promyshlennosti Rossijskogo Dal'nego Vostoka [Structural Changes in Regional Territorial and Sectorial Systems of the Russian Far East]. Vladivostok, Dalnauka Publ., 2008. 266 p.

4. Moshkov A.V. Struktyrnye sdvigi v prommyshlennom proizvodstve Tihookeanskikh regionov Rossii [Structural Shifts in industrial Production in the Pacific Regions of Russia]. Uchenye zapiski Gosudarstvennogo Zabajkal'skogo universiteta - Scholarly Notes of Transbaikal State University, 2015, no. 1, pp. 98-106.

5. Regiony Rossii: Social'no-economicheskie pokazateli 2007. Statisticheskii sbornik [Regions of Russia: Socio-economic indicators. Statistical Digest]. Moscow, Rosstat Publ., 200. $991 \mathrm{p}$.

6. Regiony Rossii: Social'no-economicheskie pokazateli 2010. Statisticheskii sbornik [Regions of Russia: Socio-economic indicators. Statistical Digest]. Moscow, Rosstat Publ., 2010. 996 p.

7. Regiony Rossii: Social'no-economicheskie pokazateli 2012. Statisticheskii sbornik [Regions of Russia: Socio-economic indicators. Statistical Digest]. Moscow, Rosstat Publ., 2012. $990 \mathrm{p}$.

8. Regiony Rossii: Social'no-economicheskie pokazateli 2013. Statisticheskii sbornik [Regions of Russia: Socio-economic indicators. Statistical Digest]. Moscow, Rosstat Publ., 2013. 990 p.

9. Regiony Rossii: Social'no-economicheskie pokazateli 2016. Statisticheskii sbornik [Regions of Russia: Socio-economic indicators. Statistical Digest]. Moscow, Rosstat Publ., 2016. $1326 \mathrm{p}$.

10. Regiony Rossii: Social'no-economicheskie pokazateli 2018. Statisticheskii sbornik [Regions of Russia: Socio-economic indicators. Statistical Digest]. Moscow, Rosstat Publ., 2018. 1162 p.

11. Romanov M. T. Territorial'naya organizatsiay khozyastva slaboosvoennykh regionov Rossii [Territorial Organization of the Economy of Poorly Developed Regions of Russia]. Vladivostok, Dalnauka Publ., 2009. 317 p.

12. Strategiya territorial'noj organizacii hozyajstva Primorskogo kraya [Strategy of the territorial organization of the economy of the Primorsky Territory]. Vladivostok, Dalnauka Publ., 1991. 260 p.

13. Tihookeanskaya Rossiya: stranicy, proshlogo, nastoyashchego, budushchego [Pacific Russia: pages of the past, present, future]. Vladivostok, Dalnauka Publ., 2012. $406 \mathrm{p}$.

14. Baklanov P. Ya., Moshkov A. V. Structural transformation of the economy in the Pacific region of Russia and efficiently trends. R-ECONOMY, 2016, no. 1, pp. 51-66.

15. Baklanov P. Ya., Romanov M. T., Karakin V. P., Lankin A. S. Projects of Development of Transcontinental Transport-Economic Belts in Northern Russia. Journal of Resources and Ecology, 2015, no. 6, pp. 110-113. 